\section{DNA-binding motif}

SIR-We wish to point out that a basic motif implicated in sequence-specific DNA binding in the Fos/Jun family of proteins is structurally conserved in the Myc proteins and in other regulatory factors that are proposed ${ }^{1}$ to contain amphipathic helix-loop-helix (A-HLH) domains. In addition to the Myc proteins, this group includes the muscle determination factors MyoD1 and myogenin, the kappa enhancer-binding proteins E12 and E47, and the polypeptides encoded by the Drosophila genes daughterless, twist and achaetescute T4/T5.

In the Fos/Jun proteins, the 'leucine zipper' region has been shown to be critical for dimerization, while sequencespecific DNA binding by Fos/Jun requires the integrity of a basic motif immediately amino-terminal to the leucine zipper ${ }^{2,3}$. Similarly, in the case of the E12/E47 enhancer-binding proteins, integrity of the proposed A-HLH domain has also been shown to be important for protein 'dimerization and DNA-binding activityl. The carboxy-terminal region of c-Myc (amino acids 369-439), containing both the leucine zipper and A-HLH motif, has been shown to be sufficient for protein oligomerization in vitro ${ }^{4}$.

The incorporation of domain definitions in a visual comparison of the region just amino-terminal of the dimerization motifs in the Fos/Jun and A-HLH proteins

\section{Memory T cells}

SIR-Haregewoin et al. ' have reported the exciting finding of a human $\mathrm{T}$-cell line expressing a $\gamma \delta$ T-cell receptor (TCR). The $\mathrm{T}$-cell line $\left(\mathrm{CD}_{2}{ }^{+}, \mathrm{CD}^{+}, \mathrm{CD} 16^{-}\right)$ responds to PPD (purified protein derivative) and a mycobacterial heat-shock protein of relative molecular mass 65,000 (65K HSP) in a self-restricted fashion. The line was obtained by stimulation of peripheral-blood mononuclear cells with PPD, followed by depletion of CD4, CD8 and $\alpha \beta$ TCR expressing cells. Cells were maintained by repeated restimulation with autologous antigenpresenting cells, antigen and T-cell growth factor.

We have shown that recall-antigenreactive 'memory' $\mathrm{T}$ cells occur with high frequencies in freshly isolated $\mathrm{CD} 45 \mathrm{RO}^{+}$/ $\mathrm{UCHL1}^{+}$, but not CD45RA ${ }^{+}$, populations of human lymphocytes ${ }^{2}$. Haregewoin et al. speculate in reference to this work, that their line may be derived from memory $\mathrm{T}$ cells, as it is $\mathrm{CD} 45 \mathrm{R} 0^{+} / \mathrm{UCHL1}^{+}$and CD45RA . We would like to point out that after activation in vitro, CD45RA ${ }^{+} \mathrm{T}$ cells lose CD45RA (refs 3-7) and acquire reactivity with the $C D 45 R 0$ reagent UCHL1 (refs 6 and 7). The expression of CD45R0 on Jl-2 dependent T-cell lines

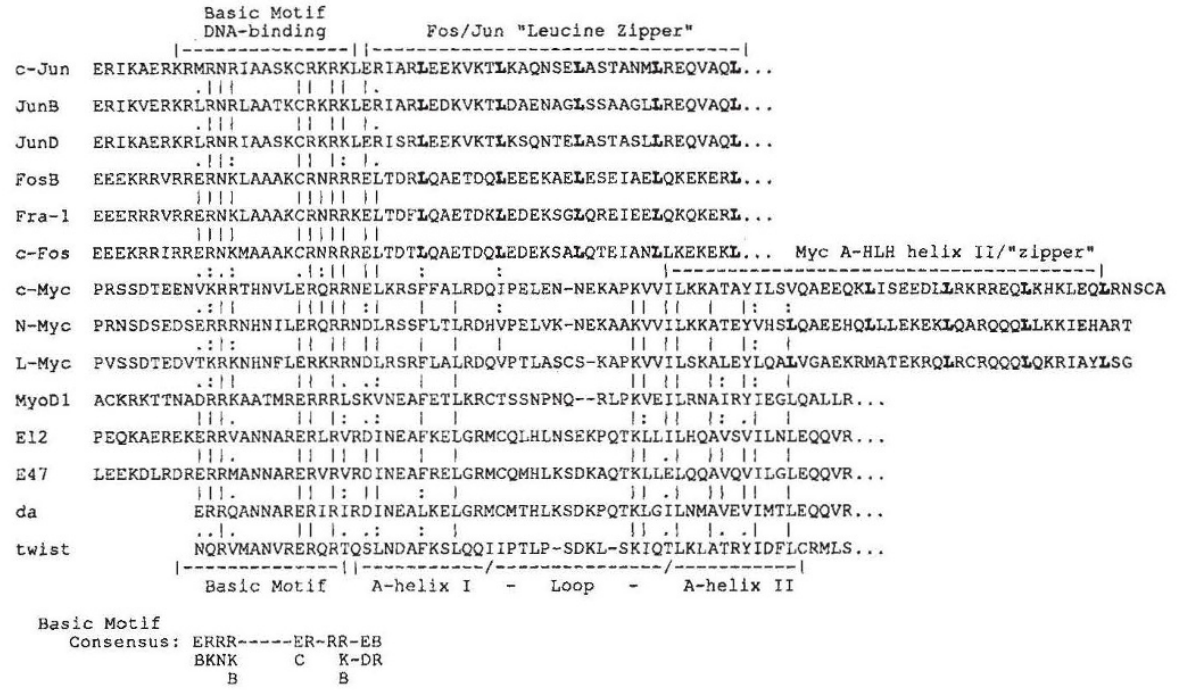

Basic motif and oligomerization domain similarities between Fos/Jun and A-HLH gene regulatory proteins. The single-letter amino acid code is used; $B$ represents a hydrophobic amino acid. Identity is noted by dashes, similarities by dots. Amino-acid sequence is shown for mouse c-Jun (254-311), JunB (239-314) and JunD (261-318) (see ref. 6); mouse FosB (154-211), Fra-1 (106-163) and c-Fos (136-195) (see ref. 7); human c-Myc (337-439), N-Myc (384-462), L-Myc (280-363), MyoD (99-164), E12 (327-393), E47 (327-393), daughterless (554-613) and twist (357-407) (see ref. 1).

reveals a 17-amino-acid block of structural similarity (see figure). The highest similarity (about 45 per cent with conservative substitutions) is between the Fos and Myc proteins. We noted that this region is positioned exactly in register with hydrophobic amino acids critical for the helix-helix interactions that mediate dimerization by the leucine zipper and (proposed for) the

and clones is, therefore, a regular finding which does not provide any information on the CD45 phenotype of their precursor cells.

Our group has recently demonstrated the expression of CD45R0 by a proportion of freshly isolated $\gamma \delta$ TCR T cells. This proportion is low in very young children and rises with age $^{8}$, as is the case for $\alpha \beta$ TCR T cells. This observation is consistent with the accumulation of $\gamma \delta$ memory $T$ cells, a possibility that could be tested now that some antigens to which human $\gamma \delta \mathrm{T}$ cells respond have been defined $^{1.9 .10}$.

MATTHIAS MERKENSCHLAGER PETER C. L. BEVERLeY ICRF Human Tumour Immunology Group, 91 Riding House Street, London W1P 8BT, UK

1. Haregewoin, A. et al. Nature 340, 309-312 (1989)

2. Merkenschlager, M. et al. Eur. J. Immunol. 18, 1653 1661

3. Tedder, T.F., Clement, L.T. \& Cooper, M. J. Immunol 134, 2983-2993 (1985).

4. Moore, K. \& Nesbitt, A.M. Immunology 61, 159-165 (1987).

5. Serra, H.M. et al. J. Immun. 140, 1435-1441 (1988)

6. Terry, L., Pickford, A. \& Beveriey, P.C.L. in Leucocyte Typing 3 (eds McMichael, A. et al.) 225-227 (Oxford University Press, 1987).

7. Akbar, A. et al. J. Immun. 140, 2171-2178 (1988).

8. Hayward, A.R., Lee, J. \& Beverley, P.C.L. Eur. J. Immun. 19, 771-773 (1989)

Holoshitz, J., Koning, F., Coligan, J.,E., De Bruyn, J. \& Strober, S. Nature 339, 226-229 (1989).

10. Modlin, R.L. et al. Nature 339, 544-548 (1989).
HLH helix 1. Strikingly, the region overlaps that part of the basic motif in Fos which is necessary for specific DNA-binding to the AP1 recognition sequence ${ }^{2-4}$. The significance of this similarity is founded on the incorporation of biological meaning (that is, definition of domains) into the search. (Homology search algorithms give this similarity a high quality score when the Fos basic motif region is used in database comparisons.)

On the basis of this structural similarity, we propose that the basic motif in the Myc and A-HLH proteins is likely to encode a sequence-specific DNA-binding function. With regard to the Myc proteins, though a specific DNA recognition site is yet to be identified, our proposal contrasts with suggestions that this function is encoded in the A-HLH domain ${ }^{1}$, or in a more aminoterminal region (amino acids 285-318) required for nonspecific DNA bindings. The structural similarity between A-HLH and Fos/Jun proteins in this domain suggests that these proteins are part of a large 'basic motif' family evolutionarily related via their DNA-binding structures. This family would contain at least three subsets comprising members that contain only leucine zippers, only A-HLH domains or both.

\section{GEORGE C. PRENDERGAST} EDWARD B. ZIFF

Department of Biochemistry,

New York University Medical Center,

New York, New York 10016, USA

1. Murre, C. et al. Cell 56, 777-783 (1989)

2. Kouzarides, T. \& Ziff, E. Nature 336, 646-651 (1988)

3. Neuberg, M., Schuermann, M., Hunter, J.B. \& Müller, R Nature 338, 589-590 (1989).

4. Dang, C.V. et al. Nature 337, 664-666 (1989).

5. Dang, C.V. et al. Molec. cell. Biol. 9, 2477-2486 (1989)

6. Hirai, S.-1. et al. EMBO J. 8, 1433-1439 (1989).

7. Zerial, M. et al. EMBO J. 8, 805-813 (1989). 